\title{
Biologics for the treatment of moderate- to-severe ulcerative colitis in pediatric patients
}

This article was published in the following Dove Press journal:

Pediatric Health, Medicine and Therapeutics

18 July 2012

Number of times this article has been viewed

\author{
Lindsey G Albenberg \\ Petar Mamula \\ Judith R Kelsen \\ Division of Gastroenterology, \\ Hepatology, and Nutrition, The \\ Children's Hospital of Philadelphia, \\ Philadelphia, PA, USA
}

\begin{abstract}
Ulcerative colitis (UC) is a chronic, inflammatory disease of the large intestine. In pediatric patients, $\mathrm{UC}$ is associated with significant morbidity including persistent symptoms affecting quality of life, hospitalizations, and surgery, and therapeutic strategies are limited. The advent of biologics, specifically anti-tumor necrosis factor- $\alpha$ medications, has been very beneficial for pediatric patients suffering from UC. Since the introduction of these therapies, there has been improvement in the rates of both remission as well as colectomy-free survival. However, there has been concern regarding the adverse events associated with these medications including the risk of infection and malignancy. The efficacy and safety of infliximab, the most frequently used biologic medication in pediatric patients with UC, will be the focus of this review.
\end{abstract}

Keywords: ulcerative colitis, biologics, anti-TNF- $\alpha$, infliximab, adalimumab

\section{Introduction}

Ulcerative colitis (UC) is a form of chronic, inflammatory bowel disease (IBD) characterized by relapsing inflammation of the large intestine including the rectum. Both of the inflammatory bowel diseases, Crohn disease (CD) and UC, are associated with significant morbidity. The etiology of these diseases is unclear, but appears to involve an abnormal immune response to environmental factors in a genetically susceptible host. While the diagnosis of IBD can occur at any age, up to $25 \%$ of patients will become symptomatic during childhood or adolescence. ${ }^{1}$ The pediatric literature suggests that the highest age-related occurrence of UC occurs in patients greater than 10 years of age. ${ }^{2}$ In North America, for example, the incidence of UC in patients 10-19 years of age is thought to be approximately two cases per 100,000 persons. ${ }^{3}$ Similar incidences have been described in Europe. ${ }^{4-6}$ In terms of prevalence, population-based studies suggest that IBD, in general, is unevenly distributed throughout the world, with the highest disease rates occurring in industrialized nations. ${ }^{7,8}$ Also, it has been demonstrated that people who immigrate to Westernized countries have a higher rate of developing IBD, especially UC. ${ }^{9}$ UC affects the rectum with contiguous proximal involvement that can include the entire large intestine. Patients typically present with chronic symptoms of abdominal pain, diarrhea, and rectal bleeding. Rectal bleeding is the most frequently observed symptom and is thought to occur in approximately $83 \%-95 \%$ of pediatric patients with UC. ${ }^{10}$ In the pediatric population, the presentation of symptoms is variable. However, children frequently present with more extensive disease as compared to adults and thus are more likely to experience acute, severe symptoms at the time of diagnosis. ${ }^{11}$ A statewide epidemiological study in Wisconsin ${ }^{12}$ evaluating pediatric 
patients newly diagnosed with IBD found left-sided colitis in only $10 \%$ of children with UC at the time of presentation. Conversely, $90 \%$ of children presented with pancolitis. ${ }^{12}$

There are clear phenotypic differences between adult and pediatric patients with UC. In addition, in pediatric UC, the disease extent often changes with time. ${ }^{13}$ In a cohort of 113 pediatric patients newly diagnosed with UC, for example, proximal disease extension according to Montreal Classification occurred in $49 \%$ of patients with a median follow-up time of 6 years. ${ }^{14}$ Because pediatric patients with UC represent a unique population, the Montreal Classification was recently modified and renamed the Paris Classification. ${ }^{13}$ In terms of disease extent, a fourth category was added to the Montreal Classification and thus disease extent can be classified as patients with proctitis (E1), patients with leftsided colitis distal to the splenic flexure (E2), patients with extensive colitis distal to the hepatic flexure (E3), or patients with pancolitis (E4). To designate severity (S0 or S1), the Paris Classification incorporates the Pediatric Ulcerative Colitis Activity Index (PUCAI) score. The PUCAI score is a validated, noninvasive tool developed to measure disease activity in pediatric UC and will be discussed in more detail later in this review. ${ }^{15}$

In general, the symptoms of UC reflect the extent of colonic inflammation. Patients with proctitis present with diarrhea and hematochezia and there are no systemic findings such as fever, weight loss, or hypoalbuminemia. There is usually good response to therapy. In left-sided colitis, patients present with abdominal cramping and tenderness, bloody diarrhea, and urgency to defecate. Associated systemic findings may be present and the treatment of the left-sided disease may be more challenging. Finally, the presentation of extensive colitis or pancolitis involves abdominal pain and tenderness, multiple bloody stools per day, nocturnal bowel movements, urgency, and tenesmus. Systemic manifestations are common such as fever, leukocytosis, anemia, and hypoalbuminemia. Patients who present with extensive, severe UC are at risk for life-threatening complications including severe hemorrhage, toxic megacolon, and intestinal perforation. Severe UC may be refractory to medical management and in some patients, surgical removal of the colon may be required. In fact, it is believed that there is a relationship between disease severity at presentation and a need for colectomy within 5 years of diagnosis. ${ }^{16}$

The goals for managing UC are to eliminate symptoms of disease, improve quality of life, and avoid hospitalization and surgery (colectomy). In pediatric patients, some of the additional aims are to promote and allow normal, unrestricted activity (ie, attending school) and to ensure optimal nutrition, bone health, and growth. Maintenance of corticosteroid-free remission is also critical. Therapies are generally targeted at key positions in the inflammatory pathway. However, with growing knowledge regarding the pathogenesis of $\mathrm{UC}$, a more individualized approach, which takes into account a person's genetics and gut microbiota, is imminent.

For many years, well-established therapies such as aminosalicylates and immunomodulators 6-mercaptopurine have been used in a step-up fashion in the treatment of pediatric UC. However, the more recent development and use of biologic agents that target key inflammatory molecules, such as TNF- $\alpha$, has transformed the approach to the medical management of UC. Multiple studies, in adults as well as in children with IBD, have demonstrated that biologic medications are effective in the induction and maintenance of symptomatic remission. Although clinical improvement is an obvious goal of the therapy, the literature currently suggests that in order to increase the chance of lasting remission and decrease the potential for adverse effects of long-standing inflammation, it is important to attain mucosal healing. ${ }^{17}$ Biologic therapy has the ability to induce and maintain mucosal healing and, therefore, has led to more valiant treatment goals. ${ }^{18}$

\section{The role of TNF- $\alpha$ in inflammatory bowel disease}

Tumor necrosis factor- $\alpha$ (TNF- $\alpha$ ) is an important pro-inflammatory cytokine in the development of IBD. It is produced by macrophages and T-lymphocytes and is responsible for the induction of many additional cytokines, which further perpetuate the inflammatory process. Interestingly, TNF- $\alpha$ has been found in increased concentrations in the blood, colonic tissue, and stool of patients with UC. ${ }^{19}$ Biologic medications that target the TNF- $\alpha$ molecule are effective therapies for both CD and UC. The most intensively studied anti-TNF- $\alpha$ medication is infliximab, a chimeric IgG1 monoclonal antibody to TNF- $\alpha$. Infliximab neutralizes TNF- $\alpha$ by binding with high affinity to both soluble and transmembrane forms of the molecule. Infliximab also inhibits the ability of TNF- $\alpha$ to bind to its receptor. Twentyfive percent of the infliximab molecule consists of murine protein. More recently, alternative anti-TNF- $\alpha$ medications such as adalimumab, certolizumab, and golimumab have been developed that consist of fully humanized protein. Several other biologic medications, including antibodies and small molecules, have also been investigated in the treatment of IBD. This includes antileukocyte adhesion molecules and inhibitors of the IL-23 inflammatory pathway. However, the 
anti-TNF- $\alpha$ medications, infliximab and adalimumab, are the most commonly used biologic medications in the treatment of pediatric UC and thus will be the focus of this review.

\section{Anti-TNF- $\alpha$ therapy in pediatric patients}

Over the years, multiple studies in both adult and pediatric patients have demonstrated that anti-TNF- $\alpha$ medications are effective in the treatment of $\mathrm{CD}^{20-25}$ For example, the $\mathrm{REACH}$ trial, a prospective, multicenter, randomized, open-label trial, was a landmark pediatric study, which established that infliximab is effective in the treatment of pediatric patients with moderately to severely active $\mathrm{CD} .^{22}$ However, the early literature evaluating the efficacy of antiTNF- $\alpha$ medications in UC yielded conflicting results; thus, the effectiveness of anti-TNF- $\alpha$ medications in UC was initially uncertain. The definitive evidence for the efficacy of infliximab in UC was provided by the adult Active Ulcerative Colitis Trials 1 and 2 (ACT 1 and ACT 2) in 2005. ${ }^{19}$ These were randomized, double-blind, placebo-controlled trials examining the efficacy of infliximab for the induction and maintenance of remission in patients with moderately to severely active UC. Both ACT 1 and ACT 2 included 364 patients who received infliximab or placebo at weeks 0,2 , and 6. In ACT 1, patients continued therapy every 8 weeks, through week 46 and were followed for a total of 54 weeks. In ACT 2, patients received therapy every 8 weeks, through week 22 and were followed for 30 weeks. Infliximab was found to be superior to placebo in the induction of and maintenance of both clinical and histological response in adult patients who had failed conventional therapy. Recently, the ACT 1 and 2 Extension Study was published. ${ }^{26}$ Patients from the original cohort, who achieved benefit with infliximab, were eligible to participate for 3 additional years of therapy. Infliximab was found to be effective and well tolerated as a long-term maintenance therapy.

The first pediatric studies evaluating the efficacy of infliximab in UC were generally small, single-center reports (see Table 1). ${ }^{27-33}$ One of the larger retrospective studies was a multicenter study by Cucchiara and colleagues, which evaluated the efficacy of infliximab, based on the Lichtiger Colitis Activity Index (LCAI), in 22 pediatric patients with UC refractory to or dependent upon corticosteroids. ${ }^{29}$

Table I The first pediatric studies evaluating the efficacy of infliximab in ulcerative colitis

\begin{tabular}{|c|c|c|c|c|c|c|}
\hline Reference & Year & Design & $\mathbf{n}$ & Subjects & Outcome measures & Short-term response \\
\hline Serrano et $\mathrm{al}^{27}$ & 2001 & Retrospective & 3 & $\begin{array}{l}\text { Patients not responding to } \\
\text { conventional therapy }\end{array}$ & $\begin{array}{l}\text { Subjective clinical } \\
\text { improvement, ESR, } \\
\text { prednisone dosage }\end{array}$ & $\begin{array}{l}\text { Clinical improvement } \\
\text { in } 3 / 3(100 \%)\end{array}$ \\
\hline Mamula et $\mathrm{al}^{28}$ & 2002 & Retrospective & 9 & $\begin{array}{l}\text { Hospitalized patients unresponsive to } \\
2 \text { wks of IV corticosteroid } \\
\text { or ambulatory patients on an } \\
\text { immunomodulator with no response or } \\
\text { incomplete response to corticosteroid }\end{array}$ & $\begin{array}{l}\text { LCAI and PGA at } \\
2 \text { days and } 2 \text { weeks } \\
\text { post-infusion }\end{array}$ & $\begin{array}{l}\text { Decreased PGA in } 7 / 9 \\
(77 \%) \text {; inactive disease } \\
\text { by LCAI in } 6 / 9(66 \%) \text { at } \\
2 \text { weeks }\end{array}$ \\
\hline Russell et $\mathrm{al}^{32}$ & 2004 & Retrospective & 14 & $\begin{array}{l}\text { Group I: newly diagnosed, fulminant } \\
\text { colitis refractory to 7-I0 d of IV } \\
\text { corticosteroid } \\
\text { Group 2: relapsed UC refractory } \\
\text { to } 710 \mathrm{~d} \text { of IV corticosteroid } \\
\text { Group 3: steroid dependent UC not } \\
\text { responding to conventional therapy }\end{array}$ & LCAI & $\begin{array}{l}\text { Group I: } 5 / 5(100 \%) \\
\text { Group 2: } 3 / 4(75 \%) \\
\text { Group 3: } 1 / 5(20 \%)\end{array}$ \\
\hline Eidelwein et $\mathrm{al}^{30}$ & 2005 & Retrospective & 12 & $\begin{array}{l}\text { Fulminant colitis }(n=3) \text {, acute } \\
\text { exacerbation of colitis }(n=3) \text {, } \\
\text { steroid-dependent colitis }(n=5) \text {, } \\
\text { steroid-refractory colitis }(n=1)\end{array}$ & $\begin{array}{l}\text { Physician assessment of } \\
\text { abdominal pain, stool } \\
\text { frequency, rectal bleeding }\end{array}$ & $\begin{array}{l}\text { Short-term response } \\
\text { in } 12 / 12(100 \%) \text {; } \\
\text { complete resolution of } \\
\text { symptoms in } 9 / 12(75 \%) \text {, } \\
\text { partial improvement in } \\
\text { symptoms in } 3 / 12(25 \%)\end{array}$ \\
\hline Cucchiara et al $^{29}$ & 2008 & Retrospective & 22 & $\begin{array}{l}\text { Severe UC refractory to corticosteroid } \\
(n=4) \text {, steroid-dependent colitis }(n=16) \text {, } \\
\text { steroid-refractory colitis }(n=2)\end{array}$ & $\mathrm{LCAl}$ & $\begin{array}{l}\text { Response in } 12 / 22(55 \%) \text {, } \\
\text { partial response in } 6 / 22 \\
(27 \%) \text {, no response in } \\
4 / 22(18 \%)\end{array}$ \\
\hline McGinnis et $\mathrm{al}^{31}$ & 2008 & Retrospective & 46 & Steroid-resistant or dependent UC & $\begin{array}{l}\text { Post-treatment } \\
\text { recategorization into } \\
\text { Truelove and Witts } \\
\text { "mild" category or better }\end{array}$ & $\begin{array}{l}\text { Clinical response in } 28 / 40 \\
(70 \%)\end{array}$ \\
\hline
\end{tabular}

Abbreviations: ESR, erythrocyte sedimentation rate; IV, intravenous; LCAI, Lichtiger Colitis Activity Index; PGA, Physician global accessment; UC, ulcerative colitis. 
Response or partial response was seen in the majority of patients (55\% and $27 \%$, respectively). A small, prospective study of Brazilian children with IBD treated with infliximab demonstrated improvement in clinical manifestations in all patients. ${ }^{33}$ Of the seven patients with UC, five (71\%) experienced a significant reduction in the PUCAI score. The remainder of the initial studies is summarized in Table 1. The majority of these studies demonstrated clinical improvement, at least in the short term. However, long-term outcomes of infliximab therapy in pediatric UC were initially uncertain.

In 2004, we reported 2-year follow-up data to our initial case series, ${ }^{28}$ which demonstrated that infliximab treatment was associated with both short-term and long-term benefit in pediatric patients with UC who were refractory to conventional therapy. ${ }^{34}$ Short-term improvement was seen in $82 \%$ of patients ${ }^{28}$ and prolonged improvement was seen in $63 \%$ of patients. ${ }^{34}$ More recently, Hyams and colleagues performed a multicenter, prospective, observational cohort study of 332 pediatric patients with UC. ${ }^{35}$ In this study, $61 \%$ of patients who had failed intravenous corticosteroids and had been prescribed infliximab as a second-line therapy, avoided colectomy at 24 months. In addition, at 12 and 24 months, $28 \%$ and $21 \%$ of patients were in remission and off corticosteroids, respectively. ${ }^{35}$ These data were consistent with a recent large, multicenter, retrospective study in adults with UC, which demonstrated long-term (greater than 1 year) maintenance of mucosal healing as well as improved rates of colectomy-free survival. ${ }^{36}$

Adalimumab is a fully humanized monoclonal antibody, which also binds TNF- $\alpha$. Generally, adalimumab is used in patients who either lose response or become intolerant to infliximab. The time to remission for adalimumab may be slower as compared to infliximab, which makes it somewhat less suitable for the treatment of acute, severe exacerbations. ${ }^{37}$ The Retrospective Evaluation of the Safety and Effect of Adalimumab Therapy (RESEAT) study was a large, multicenter description of adalimumab therapy in pediatric CD. ${ }^{25}$ Adalimumab was found to be well tolerated and effective in the treatment of moderately to severely active CD. More recently, adalimumab was studied in a prospective fashion and was demonstrated to be safe and effective in the treatment of pediatric CD. ${ }^{38}$ Adalimumab has been used in the treatment of ulcerative colitis, although it is currently not US Food and Drug Administration (FDA)-approved for this indication. Recently, the efficacy of adalimumab was evaluated in adult patients with UC. ${ }^{39}$ In a controlled and double-blinded study by Sandborn and colleagues, adalimumab was found to be safe and more effective than placebo for the induction and maintenance of remission in patients with moderate-to-severe UC refractory to conventional therapy. ${ }^{39}$ Very little data, however, exist regarding the use of adalimumab in pediatric UC and there have been no prospective trials. In a small, retrospective study of ten pediatric patients with IBD treated with adalimumab because of either lack of or loss of response to infliximab, three patients with UC achieved improvement in the LCAI in the short term. ${ }^{40}$ However, one of these patients later failed adalimumab and required colectomy. ${ }^{40}$ This study included a very small number of UC subjects and, clearly, larger studies are required to determine the efficacy of adalimumab in pediatric UC. There are no reports on the use of certolizumab pegol and golimumab in the pediatric population with UC.

Taken together, the available pediatric literature supports the use of anti-TNF- $\alpha$ medications in the treatment of ulcerative colitis. In fact, in 2011, the FDA approved infliximab for the treatment of moderately to severely active UC in children older than 6 years in the setting of inadequate response to conventional therapy. The infliximab dose used in pediatric patients is $5 \mathrm{mg} / \mathrm{kg}$. Similar to the adult population, intravenous infusions are given at 0,2 , and 6 weeks for induction. Infusions are then administered every 8 weeks for maintenance of remission. However, when there is inadequate response, especially in the setting of subtherapeutic infliximab trough levels, the dosage may be increased (up to $10 \mathrm{mg} / \mathrm{kg}$ ) or the dosing interval may be decreased.

As mentioned in the introduction, the inflammatory bowel diseases are associated with significant morbidity and this high morbidity has led to a substantial public health burden. ${ }^{41}$ A recent study describing the direct health care costs of CD and UC in US children and adults ${ }^{42}$ demonstrated significantly increased annual healthcare costs for patients with $\mathrm{CD}$ and UC as compared to non-IBD controls. Not surprisingly, in IBD patients, pharmaceuticals accounted for the largest proportion of direct costs and infliximab was the most costly medication. In this study, as compared to prior studies, pharmaceutical costs had increased while IBD-related hospitalization costs had decreased. This study and others ${ }^{43,44}$ have suggested that in the era of expensive anti-TNF medications, at least some of the increased pharmaceutical costs may be offset by a subsequent decrease in hospitalizations and surgeries.

\section{Immunogenicity and safety of biologic medications}

One of the most frequently encountered side effects of infliximab is the formation of antibodies (ATI) to the murine 
portion of the drug. ATIs can be associated with acute infusion reactions, delayed hypersensitivity, and loss of response. ATIs develop in approximately $35 \%$ of pediatric patients. ${ }^{45,46}$ The prevalence of acute infusion reactions varies between studies; however, it ranges between $15 \%-20 \%$. Similar to the adult data, infusion reactions in the pediatric population were detected in $15 \%$ of all 432 infusions. ${ }^{47}$ In the REACH study, $16.1 \%$ of patients developed infusion reactions. ${ }^{22}$ In the largest series of pediatric patients reported to date, 1652 infliximab infusions were administered at six centers ${ }^{48}$ and a similar $16.5 \%$ rate of infusion reactions was seen. Acute infusion reactions are clinically manifested by shortness of breath, chest pain, palpitations, hypotension, urticaria, and headache. In cases of mild reactions, these situations can be controlled by decreasing the rate of the infusion, followed by administration of antihistamines and/or hydrocortisone if needed. In severe cases, the infusion is often stopped followed by the administration of epinephrine and the above medications. ${ }^{49}$ Subsequent infusions are then frequently preceded by corticosteroids and/or antihistamines. The most efficient method to prevent development of ATIs is systematic therapy rather than episodic treatment. ${ }^{50}$ Development of infusion reactions and ATIs do not completely preclude further use of this agent, but is often the reason therapy is changed to a humanized version of this antibody such as adalimumab.

Delayed infusion reactions, or serum sickness reactions, typically occur 4-9 days following an infusion. These reactions usually occur with episodic therapy and long treatment intervals. ${ }^{50}$ Standard induction therapy including three doses at the beginning of treatment with infliximab has been shown to reduce the incidence of delayed hypersensitivity reactions. ${ }^{50}$

The formation of autoantibodies such as antinuclear antibodies (ANA) and antibodies to double-stranded DNA (anti-dsDNA) has also been associated with the use of anti-TNF- $\alpha$ therapy. ${ }^{51}$ Drug-induced lupus is a rare occurrence and in general, the development of autoimmunity has not been associated with adverse outcomes. Discontinuation of therapy with infliximab usually resolves most complications. ${ }^{51}$ There are currently no guidelines to routinely screen for autoantibodies.

Biologic therapy is associated with an increased risk of infection. Specifically, there is an increased risk of reactivation of latent tuberculosis (TB) associated with anti-TNF- $\alpha$ therapy. ${ }^{52}$ It is currently recommended that all patients who are to begin treatment with an anti-TNF- $\alpha$ medication are screened for latent TB. In terms of the risk of other infections associated with biologic therapy, the majority of the pediatric data comes from the REACH study. ${ }^{22}$ In the REACH study, depending on the arm, the infliximab dosing interval was either q 8 week or q12 week. There appeared to be a greater risk of infection in the q8 week arm compared to the q12 week arm ( $73 \%$ versus $38 \%$, respectively). The infections included abscess, pneumonia, enterocolitis, and herpes zoster. Similar infections were also reported in a recent study of the efficacy and safety of adalimumab in pediatric patients with $\mathrm{CD} .{ }^{38}$ Aside from infections, biologic therapy has also been associated with neutropenia, ${ }^{53}$ psoriasis, ${ }^{54}$ and vasculitis ${ }^{55}$ in pediatric patients with UC.

Malignancies reported in children using ant-TNF- $\alpha$ medications have raised concerns of a potential increased risk. In 2010, the FDA's Adverse Event Reporting System was searched to identify malignancies associated with anti-TNF- $\alpha$ medications in children $0-18$ years of age. ${ }^{56}$ There were 48 reports of malignancy and 31 of these cases occurred following infliximab therapy while the remainder occurred following adalimumab or etanercept use. Of the 31 malignancies associated with infliximab, hepatosplenic T-cell lymphoma $(n=9)$ was the most common followed by non-Hodgkin's lymphoma ( $\mathrm{n}=5)$, Hodgkin's lymphoma $(\mathrm{n}=3)$, and leukemia $(\mathrm{n}=3)$. Patients with IBD accounted for 24 of the 31 cases and included all of the cases of hepatosplenic T-cell lymphoma (HSTL). The authors concluded that there may be an increased risk of cancer in children treated with anti-TNF medications. However, because many of the patients were being treated with concomitant medications, including immunosuppressive medications, a causal relationship could not be established. Kotlyar and colleagues later described 36 cases of hepatosplenic T-cell lymphoma in patients with IBD. ${ }^{57}$ The majority of cases occurred in male patients younger than 35 years. Interestingly, there were no cases of HSTL in patients who were treated with an antiTNF- $\alpha$ medication alone. All patients were either treated with an immunomodulator as monotherapy or with a combination of an immunomodulator and an anti-TNF- $\alpha$ medication. There were no malignancies reported in the REACH study, although follow-up may have been too short. Presently, there appears to be an increased risk of malignancies associated with anti-TNF- $\alpha$ therapy. However, studies to date are limited by confounding factors including concomitant use of other immunosuppressive medications.

\section{The use of infliximab in fulminant disease}

As discussed previously, pediatric patients with UC often present with acute, severe disease and in these situations, 
the treatment options are limited. Corticosteroids are considered to be first-line therapy in acute, severe exacerbations. However, approximately $1 / 3$ of pediatric patients with severe UC will not have a complete response to corticosteroids. There are several indices used early on in the course of therapy in the adult population to help predict which patients will fail to respond to corticosteroids. ${ }^{58}$ In these patients, "rescue" therapies, such as biologics, can then be promptly instituted. Until recently, no such tool existed in pediatrics. In 2007, the PUCAI was developed. ${ }^{59}$ The PUCAI uses noninvasive items such as degree of abdominal pain, amount of rectal bleeding, and number of stools per 24 hours to measure disease activity in pediatric UC. The PUCAI was initially validated by means of a prospective cohort of 48 pediatric patients with ulcerative colitis undergoing colonoscopy. The PUCAI correlated well with established indices including the Beattie index, Physician global assessment (PGA), and Mayo score. ${ }^{59}$ More recently, the PUCAI was prospectively evaluated in 215 children with UC. ${ }^{15}$ This study confirmed the validity of the PUCAI as a primary outcome measure in determining disease activity in pediatric UC. ${ }^{15}$

The PUCAI score is now used commonly to direct therapeutic decisions in pediatric patients presenting with severe, acute UC. ${ }^{60}$ For example, a PUCAI of greater than 45 on day 3 can be used to predict nonresponse to IV corticosteroids. ${ }^{11}$ In addition, patients who have a calculated PUCAI of greater than 70 on day 5 of corticosteroids should be regarded as steroid refractory and rescue therapy with infliximab should be considered. ${ }^{11}$ Recently, a multicenter, prospective, observational study was designed in order to evaluate outcomes in severe pediatric $\mathrm{UC},{ }^{61}$ in which pediatric patients hospitalized for severe UC were enrolled. The PUCAI, calculated on days 3 and 5 of IV corticosteroid treatment, was able to predict patients who would require rescue therapy. Of the patients $(29 \%)$ who required rescue treatment with infliximab, 76\% responded and 52\% remained well 1 year following initiation of therapy. Clearly, there is a role for biologics early in the course of therapy in certain pediatric UC patients with severe disease.

\section{The effect of infliximab on UC outcomes}

At some point during the course of the illness, surgical removal of the colon may become a necessity for patients with UC. In pediatrics, $40 \%$ of patients require colectomy 10 years after diagnosis. ${ }^{62}$ The most commonly performed procedure in children with UC is the ileal pouch-anal anastomosis (IPAA). Because, in UC, the disease is limited to the colon, IPAA is considered a curative procedure. However, postoperative surgical, inflammatory, and functional complications are relatively common ${ }^{63}$ and thus medical management is favored when feasible. In 2005, Jarnerot and colleagues published the first randomized, placebo-controlled study of infliximab as a rescue therapy to prevent colectomy in hospitalized adult patients with severely active UC. ${ }^{64}$ In this study, 45 patients who did not respond to IV corticosteroids on day 4 of hospitalization were randomized to receive either one dose of infliximab $(5 \mathrm{mg} / \mathrm{kg})$ or placebo. At 3 months, $67 \%$ of patients treated with infliximab avoided colectomy compared to $29 \%$ of patients in the placebo group. Subsequently, in a follow-up evaluation of the ACT-1 and ACT-2 cohort, the incidence of colectomy through 54 weeks was $10 \%$ for infliximab and $17 \%$ for placebo $(P=0.02){ }^{65}$

It appears that infliximab therapy is also effective for the prevention of colectomy in pediatric patients with UC. For example, in the era of infliximab, Turner and colleagues reported short-term and 1-year colectomy rates of $9 \%$ and $19 \%$ respectively in pediatric patients with acute, severe UC. ${ }^{61}$ This 1-year colectomy rate was significantly lower than the rate reported in a historical cohort, of $42 \% .{ }^{66}$ In terms of moderately to severely active UC, in patients treated with maintenance infliximab, the Hyams et al. study demonstrated that $61 \%$ of patients had remained colectomy-free at 2 years. ${ }^{35}$ There have been no studies in pediatric patients with UC evaluating long-term outcomes with infliximab therapy and this should be a focus of future research.

\section{Conclusion}

Infliximab has revolutionized the approach to the medical management of children and adolescents suffering from UC. In pediatric patients with UC treated with anti-TNF- $\alpha$ medications, response and remission rates are high. Additionally, it appears that anti-TNF- $\alpha$ medications improve colectomy-free survival. The biologic medications discussed in this review appear to be safe, but are not devoid of risk. It is important to screen for latent TB and patients must be followed closely to evaluate for evidence of other infections. Finally, there is an increased risk of certain types of cancers associated with antiTNF- $\alpha$ therapy, thus careful monitoring including frequent physical examinations is required. Of course, it is critical that the benefits and the risks of biologic medications are discussed with the patient and family prior to the initiation of therapy.

\section{Disclosure}

The authors report no conflicts of interest in this work.

\section{References}

1. Kelsen J, Baldassano RN. Inflammatory bowel disease: the difference between children and adults. Inflamm Bowel Dis. 2008;14 Suppl 2:S9-S11. 
2. Malaty HM, Fan X, Opekun AR, Thibodeaux C, Ferry GD. Rising incidence of inflammatory bowel disease among children: a 12-year study. J Pediatr Gastroenterol Nutr. 2010;50:27-31.

3. Benchimol EI, Fortinsky KJ, Gozdyra P, Van den Heuvel M, Van Limbergen J, Griffiths AM. Epidemiology of pediatric inflammatory bowel disease: a systematic review of international trends. Inflamm Bowel Dis. 2011;17:423-439.

4. Stordal K, Jahnsen J, Bentsen BS, Moum B. Pediatric inflammatory bowel disease in southeastern Norway: a five-year follow-up study. Digestion. 2004;70:226-230.

5. Lindberg E, Lindquist B, Holmquist L, Hildebrand H. Inflammatory bowel disease in children and adolescents in Sweden, 1984-1995. J Pediatr Gastroenterol Nutr. 2000;30:259-264.

6. Hildebrand H, Finkel Y, Grahnquist L, Lindholm J, Ekbom A, Askling J. Changing pattern of paediatric inflammatory bowel disease in northern Stockholm 1990-2001. Gut. 2003;52:1432-1434.

7. Molodecky NA, Soon IS, Rabi DM, et al. Increasing incidence and prevalence of the inflammatory bowel diseases with time, based on systematic review. Gastroenterology. 2012;142:46-54. e42 quiz e30.

8. Lashner BA. Epidemiology of inflammatory bowel disease. Gastroenterol Clin North Am. 1995;24:467-474.

9. Barreiro-de Acosta M, Alvarez Castro A, Souto R, Iglesias M, Lorenzo A, Dominguez-Munoz JE. Emigration to western industrialized countries: A risk factor for developing inflammatory bowel disease. J Crohn's Colitis. 2011;5:566-569.

10. Bousvaros A, Antonioli DA, Colletti RB, et al. Differentiating ulcerative colitis from Crohn's disease in children and young adults: report of a working group of the North American Society for Pediatric Gastroenterology, Hepatology, and Nutrition and the Crohn's and Colitis Foundation of America. J Pediatr Gastroenterol Nutr. 2007;44: 653-674

11. Turner D, Griffiths AM. Acute severe ulcerative colitis in children: a systematic review. Inflamm Bowel Dis. 2011;17:440-449.

12. Kugathasan S, Judd RH, Hoffmann RG, et al. Epidemiologic and clinical characteristics of children with newly diagnosed inflammatory bowel disease in Wisconsin: a statewide population-based study. $J$ Pediatr. 2003; 143:525-531.

13. Levine A, Griffiths A, Markowitz J, et al. Pediatric modification of the Montreal classification for inflammatory bowel disease: the Paris classification. Inflamm Bowel Dis. 2011;17:1314-1321.

14. Gower-Rousseau C, Dauchet L, Vernier-Massouille G, et al. The natural history of pediatric ulcerative colitis: a population-based cohort study. Am J Gastroenterol. 2009;104:2080-2088.

15. Turner D, Hyams J, Markowitz J, et al. Appraisal of the pediatric ulcerative colitis activity index (PUCAI). Inflamm Bowel Dis. 2009;15: 1218-1223.

16. Hyams JS, Davis P, Grancher K, Lerer T, Justinich CJ, Markowitz J. Clinical outcome of ulcerative colitis in children. J Pediatr. 1996;129:81-88.

17. Dave M, Loftus EV Jr. Mucosal healing in inflammatory bowel diseasea true paradigm of success? Gastroenterol Hepatol (N Y). 2012;8: 29-38.

18. Armuzzi A, Van Assche G, Reinisch W, et al. Results of the 2nd scientific workshop of the ECCO (IV): Therapeutic strategies to enhance intestinal healing in inflammatory bowel disease. J Crohn's Colitis. 2012;4(6):492-502.

19. Rutgeerts P, Sandborn WJ, Feagan BG, et al. Infliximab for induction and maintenance therapy for ulcerative colitis. NEngl J Med. 2005;353: 2462-2476.

20. Targan SR, Hanauer SB, van Deventer SJ, et al. A short-term study of chimeric monoclonal antibody cA2 to tumor necrosis factor alpha for Crohn's disease. Crohn's Disease cA2 Study Group. $N$ Engl J Med. 1997;337:1029-1035.

21. Hanauer SB, Feagan BG, Lichtenstein GR, et al. Maintenance infliximab for Crohn's disease: the ACCENT I randomised trial. Lancet. 2002;359: $1541-1549$.
22. Hyams J, Crandall W, Kugathasan S, et al. Induction and maintenance infliximab therapy for the treatment of moderate-to-severe Crohn's disease in children. Gastroenterology. 2007;132:863-873; quiz $1165-1166$.

23. Hanauer SB, Sandborn WJ, Rutgeerts P, et al. Human anti-tumor necrosis factor monoclonal antibody (adalimumab) in Crohn's disease: the CLASSIC-I trial. Gastroenterology. 2006;130:323-333.

24. Colombel JF, Sandborn WJ, Rutgeerts P, et al. Adalimumab for maintenance of clinical response and remission in patients with Crohn's disease: the CHARM trial. Gastroenterology. 2007;132:52-65.

25. Rosh JR, Lerer T, Markowitz J, et al. Retrospective Evaluation of the Safety and Effect of Adalimumab Therapy (RESEAT) in pediatric Crohn's disease. Am J Gastroenterol. 2009;104:3042-3049.

26. Reinisch W, Sandborn WJ, Rutgeerts P, et al. Long-term infliximab maintenance therapy for ulcerative colitis: the ACT-1 and -2 extension studies. Inflamm Bowel Dis. 2012;18:201-211.

27. Serrano MS, Schmidt-Sommerfeld E, Kilbaugh TJ, Brown RF, Udall JN Jr, Mannick EE. Use of infliximab in pediatric patients with inflammatory bowel disease. Ann Pharmacother. 2001;35:823-828.

28. Mamula P, Markowitz JE, Brown KA, Hurd LB, Piccoli DA, Baldassano RN. Infliximab as a novel therapy for pediatric ulcerative colitis. J Pediatr Gastroenterol Nutr. 2002;34:307-311.

29. Cucchiara S, Romeo E, Viola F, et al. Infliximab for pediatric ulcerative colitis: a retrospective Italian multicenter study. Dig Liver Dis. 2008; 40 Suppl 2:S260-S264.

30. Eidelwein AP, Cuffari C, Abadom V, Oliva-Hemker M. Infliximab efficacy in pediatric ulcerative colitis. Inflamm Bowel Dis. 2005;11: 213-218.

31. McGinnis JK, Murray KF. Infliximab for ulcerative colitis in children and adolescents. J Clin Gastroenterol. 2008;42:875-879.

32. Russell GH, Katz AJ. Infliximab is effective in acute but not chronic childhood ulcerative colitis. J Pediatr Gastroenterol Nutr. 2004;39: 166-170.

33. Tiemi J, Komati S, Sdepanian VL. Effectiveness of infliximab in Brazilian children and adolescents with Crohn's disease and ulcerative colitis according to clinical manifestations, activity indices of inflammatory bowel disease, and corticosteroid use. J Pediatr Gastroenterol Nutr. 2010;50:628-633.

34. Mamula P, Markowitz JE, Cohen LJ, von Allmen D, Baldassano RN. Infliximab in pediatric ulcerative colitis: two-year follow-up. J Pediatr Gastroenterol Nutr. 2004;38:298-301.

35. Hyams JS, Lerer T, Griffiths A, et al. Outcome following infliximab therapy in children with ulcerative colitis. Am J Gastroenterol. 2010;105: 1430-1436.

36. Oussalah A, Evesque L, Laharie D, et al. A multicenter experience with infliximab for ulcerative colitis: outcomes and predictors of response, optimization, colectomy, and hospitalization. Am J Gastroenterol. 2010;105:2617-2625.

37. Russell RK, Wilson ML, Loganathan S, et al. A British Society of Paediatric Gastroenterology, Hepatology and Nutrition survey of the effectiveness and safety of adalimumab in children with inflammatory bowel disease. Aliment Pharmacol Ther. 2011;33:946-953.

38. Hyams JS, Griffiths A, Markowitz J, et al. Safety and efficacy of adalimumab for moderate to severe Crohn's disease in children. Gastroenterology. 2012; In press.

39. Sandborn WJ, van Assche G, Reinisch W, et al. Adalimumab induces and maintains clinical remission in patients with moderate-to-severe ulcerative colitis. Gastroenterology. 2012;142:257-265. e1-e3.

40. Noe JD, Pfefferkorn M. Short-term response to adalimumab in childhood inflammatory bowel disease. Inflamm Bowel Dis. 2008;14: 1683-1687.

41. Loftus EV Jr. The burden of inflammatory bowel disease in the United States: a moving target? Clin Gastroenterol Hepatol. 2007;5: 1383-1384.

42. Kappelman MD, Rifas-Shiman SL, Porter CQ, et al. Direct health care costs of Crohn's disease and ulcerative colitis in US children and adults. Gastroenterology. 2008;135:1907-1913. 
43. Tsai HH, Punekar YS, Morris J, Fortun P. A model of the long-term cost effectiveness of scheduled maintenance treatment with infliximab for moderate-to-severe ulcerative colitis. Aliment Pharmacol Ther. 2008; 28: 1230-1239.

44. Carter CT, Leher H, Smith P, Smith DB, Waters HC. Impact of persistence with infliximab on hospitalizations in ulcerative colitis. Am J Manag Care. 2011;17:385-392.

45. Candon S, Mosca A, Ruemmele F, Goulet O, Chatenoud L, Cezard JP. Clinical and biological consequences of immunization to infliximab in pediatric Crohn's disease. Clin Immunol. 2006;118:11-19.

46. Miele E, Markowitz JE, Mamula P, Baldassano RN. Human antichimeric antibody in children and young adults with inflammatory bowel disease receiving infliximab. J Pediatr Gastroenterol Nutr. 2004;38: 502-508.

47. Stephens MC, Shepanski MA, Mamula P, Markowitz JE, Brown KA, Baldassano RN. Safety and steroid-sparing experience using infliximab for Crohn's disease at a pediatric inflammatory bowel disease center. Am J Gastroenterol. 2003;98:104-111.

48. Jacobstein DA, Markowitz JE, Kirschner BS, et al. Premedication and Infusion Reactions with Infliximab: Results from a Pediatric Inflammatory Bowel Disease Consortium. Inflamm Bowel Dis. 2005;11: $442-446$.

49. Van Assche G, Vermeire S, Noman M, et al. Infliximab administered with shortened infusion times in a specialized IBD infusion unit: a prospective cohort study. J Crohn's Colitis. 2010;4:329-333.

50. Rutgeerts P, Feagan BG, Lichtenstein GR, et al. Comparison of scheduled and episodic treatment strategies of infliximab in Crohn's disease. Gastroenterology. 2004;126:402-413.

51. Vermeire S, Noman M, Van Assche G, et al. Autoimmunity associated with anti-tumor necrosis factor alpha treatment in Crohn's disease: a prospective cohort study. Gastroenterology. 2003;125:32-39.

52. Keane J, Gershon S, Wise RP, et al. Tuberculosis associated with infliximab, a tumor necrosis factor alpha-neutralizing agent. $N$ Engl $J$ Med. 2001;345:1098-1104.

53. Sherlock ME, Bandsma R, Ota K, Kirby-Allen M, Griffiths AM. Severe neutropenia following infliximab treatment in a child with ulcerative colitis. Inflamm Bowel Dis. 2011;17:E17-E18.

54. Hiremath G, Duffy L, Leibowitz I. Infliximab-induced psoriasis in children with inflammatory bowel disease. J Pediatr Gastroenterol Nutr. 2011;52:230-232.
55. Pastore S, Londero M, Gortani G, et al. Infliximab-related vasculitis in patients affected by ulcerative colitis. J Pediatr Gastroenterol Nutr. 2010;51:226-228.

56. Diak P, Siegel J, La Grenade L, Choi L, Lemery S, McMahon A. Tumor necrosis factor alpha blockers and malignancy in children: forty-eight cases reported to the Food and Drug Administration. Arthritis Rheum. 2010;62:2517-2524.

57. Kotlyar DS, Osterman MT, Diamond RH, et al. A systematic review of factors that contribute to hepatosplenic T-cell lymphoma in patients with inflammatory bowel disease. Clin Gastroenterol Hepatol. 2011;9: 36-41.

58. Seo M, Okada M, Yao T, Matake H, Maeda K. Evaluation of the clinical course of acute attacks in patients with ulcerative colitis through the use of an activity index. J Gastroenterol. 2002;37:29-34.

59. Turner D, Otley AR, Mack D, et al. Development, validation, and evaluation of a pediatric ulcerative colitis activity index: a prospective multicenter study. Gastroenterology. 2007;133:423-432.

60. Turner D, Travis SP, Griffiths AM, et al. Consensus for managing acute severe ulcerative colitis in children: a systematic review and joint statement from ECCO, ESPGHAN, and the Porto IBD Working Group of ESPGHAN. Am J Gastroenterol. 2011;106:574-588.

61. Turner D, Mack D, Leleiko N, et al. Severe pediatric ulcerative colitis: a prospective multicenter study of outcomes and predictors of response. Gastroenterology. 2010;138:2282-2291.

62. Shikhare G, Kugathasan S. Inflammatory bowel disease in children: current trends. J Gastroenterol. 2010;45:673-682.

63. Shen B. Diagnosis and management of postoperative ileal pouch disorders. Clin Colon Rectal Surg. 2010;23:259-268.

64. Jarnerot G, Hertervig E, Friis-Liby I, et al. Infliximab as rescue therapy in severe to moderately severe ulcerative colitis: a randomized, placebocontrolled study. Gastroenterology. 2005;128:1805-1811.

65. Sandborn WJ, Rutgeerts P, Feagan BG, et al. Colectomy rate comparison after treatment of ulcerative colitis with placebo or infliximab. Gastroenterology. 2009;137:1250-1260; quiz 1520.

66. Turner D, Walsh CM, Benchimol EI, et al. Severe paediatric ulcerative colitis: incidence, outcomes and optimal timing for second-line therapy. Gut. 2008;57:331-338.
Pediatric Health, Medicine and Therapeutics

\section{Publish your work in this journal}

Pediatric Health, Medicine and Therapeutics is an international, peerreviewed, open access journal publishing original research, reports, editorials, reviews and commentaries. All aspects of health maintenance, preventative measures and disease treatment interventions are addressed within the journal. Practitioners from all disciplines are invited to submit

\section{Dovepress}

their work as well as healthcare researchers and patient support groups. The manuscript management system is completely online and includes a very quick and fair peer-review system. Visit http://www.dovepress. com/testimonials.php to read real quotes from published authors. 